Témoigner Témoigner. Entre histoire et mémoire

Getuigen Revue pluridisciplinaire de la Fondation Auschwitz

$127 \mid 2018$

Perpétuation de la violence après 1918

\title{
Een persoonlijke visie op het werk van Felix Nussbaum: een documentaire van Lydia Chagoll
}

"Un point de vue personnel sur les œuvres de Felix Nussbaum" : un film documentaire de Lydia Chagoll

\section{Daniel Weyssow}

Traducteur : Rita Roggen

\section{CpenEdition}

Journals

Édition électronique

URL : https://journals.openedition.org/temoigner/7714

DOI : $10.4000 /$ temoigner.7714

ISSN : 2506-6390

Cet article est une traduction de :

"Un point de vue personnel sur les œuvres de Felix Nussbaum" - URL : https://

journals.openedition.org/temoigner/7719 [fr]

Éditeur :

Éditions du Centre d'études et de documentation Mémoire d'Auschwitz, Éditions Kimé

Édition imprimée

Date de publication : 1 octobre 2018

Pagination : 30-37

ISBN : 978-2-930953-076

ISSN : 2031-4183

Référence électronique

Daniel Weyssow, «Een persoonlijke visie op het werk van Felix Nussbaum: een documentaire van Lydia Chagoll», Témoigner. Entre histoire et mémoire [Online], 127 | 2018, Online op 10 février 2022, geraadpleegd op 14 février 2022. URL: http://journals.openedition.org/temoigner/7714 ; DOI: https:// doi.org/10.4000/temoigner.7714 
Met Felix Nussbaum, een biizonder empathische documentaire van Lydia Chagoll, krijgen we een uniek overzicht van het leven van de artiest, op het ritme van zijn werken. De motieven, tekens en symbolen zijn als bakens en de sleutel tot een wereld zonder hoop, veroordeeld tot de vernietiging. Ze onthullen de tegenwoordigheid van geest en de

eigenschappen van een van de grootste kunstenaars van de twintigste eeuw.

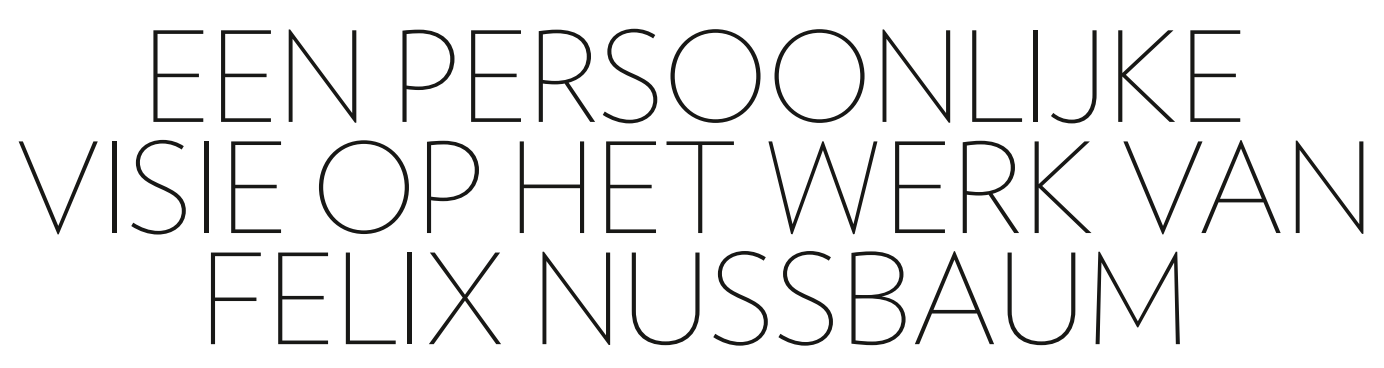

Een documentaire van Lydia Chagoll

ydia Chagoll behoeft geen inleiding. Ze is danseres, choreografe, schrijfster, cineaste en zet zich al jaren in voor de herinnering aan de slachtode genocide op de zigeuners aan te duiden). Deze om de genocide op de zigeuners aan te duiden). Deze keer brengt ze door de ogen van een schilder verslag uit van de bezetting. Het valt meteen op waarom ze je hun biografevergelijht Nussbuun met zijn landDuitsland - verlaten Dirts a Dursdehin in Duitse Acadenie in Roneword niet neer hernieuwd 列 heid krijst warop hij had gite eid eens problemen heeft ondevonden bij de verlenging de zijn verbijto 10 me 1940 door de de invasie van 10 mei 1940 door de Belgische autorihet vluchtelingent van Perpignan (Frankrijk). Hij s-Cyprien, in de buurt van hun, keert terug naar zijn echtgenote, Felka Platek, in hun woonst in de Archimedesstraat 22 in Brussel. Ze laten en vinden elders een schuilplats. Uiteindelijk

keren ze terug naar de Archimedesstraat 22, waar ze zich met de hulp van de eigenaar schuilhouden op de zolder. Hoewel ze heel voorzichtig zijn, worden ze op 20 juni 1944 aangehouden en op 31 juli met het konvoo XVI gedeporteerd naar Auschwitz.

Het parcours van Lydia Chagoll vertoont veel gelijkenis met dat van de kunstenaar. Ze werd geboren in Nederland hederland en als ze nog maar net eén jaar is, besluiten zuar ouders in 1932 om zich samen met haar en haar sie op 10 mei 1940 sluit het sie op 10 in nas rank streek rond Toulouse, waar ze naar een vluchtelingenkampinhetkasted vanLa Fourquettewordengebracht. ren gen hebben ondeno ken, belandonzeië (het huidige Indoh.ï). Ze reizen Nederlands-Indie (het huidige Indonesie). Ze reizen met de trein en de boot, doork Iisen Spanje, Portugal, Mozi vaqu Ja Zuid-Afika. Kort na hun aankoms en die van de Japanters in de archipel ziet haar vader zich gedwongen om er aan te sluiten bij het contingen van het Nederlandse leger.Lydia, haar zus en hun moeder worden weldra ans iljk wan de Jap opgesloten. Ze blijven geïnterneerd tot ein oktober 1945, dus lan nade vredesverklaring Het gerin keert'nazes Het gezin keert 'nazes jaren en zes maanden Brussel terug (Chagoll 1986, 178). Hun verhal kent een happy haal kent een happy end, maar voor Lydia was an het eind van was aan het eind van haar krachten door ziektes.

Felix Nussbaum is helemaal aanwezis is helemaal aanwezig in zijn schilderijen. Je kunt er de evolutie van zijn gemoedsgeparcours involgen $\mathrm{Hij}$ parcours in volgen. Hij is melancholisch en introvert, een observator en kunstkenZelig de held van de Zelig, de held van de gelijknamige film van Woody Allen, is hij werk van anderen. $\mathrm{Hij}$ neemt immers graas neent immers graag de stijl en de onderkunstenaars die hij belangrijk acht. Dat belangrijk acht. Dat is heel normaal voor een schilder die zich nog in zijn leerproces bevindt. Zo ontstond diet wat bewerkingen een soort creatieve pangen (realisme, expressenvan verschillende strekkingen (realisme, expressionisme, fauvisme, surrealisme, ...) en een hele reeks schilders (Vincent Van

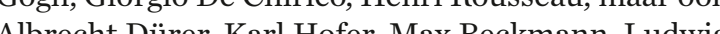
Meidnt Durer, Kar Hore, Max Becknan, Ludwig Belgen Pieter Bueghelde Oudere, Janes Ens. Paul
Delvaux Gustave Van de Woestyne, Gustave de Smet, dgard Tytgat,....

ie brede belangstelling is het niet moeiijk om een eigen stijl te herkennen, die het resultaat is van een combinatie van factoren die duidelijk Nussbaums heel persoonlijke 'signatuur' dragen en de invloed vertonen van zijn geheel eigen visie op de wereld. Die kont tot uiting in zijn onderwerpen, por- 
œ en zeegezichten, aangevuld met thema's die er al vlug overdreven en macaber gaan uitzien. Zijn werkwijze is to toeschouwer, vak alleen al door een stel ogen die je proberen vast te houd. De levensomstandigheden worden van dag tot dag moeiljker, gevaarlijker en te bedenken warin de mens en zijn ongeving steeds te bedenken walin de nons zijin ongeving steeds mer

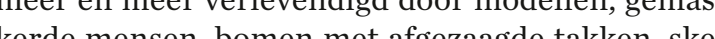
letre iijn. De tich vermengt met de dood die al

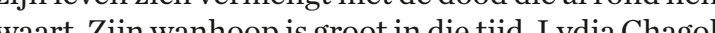
heeft dat zwarte doek uiteraard perfect ingeschat en begrepen

De film toont op een prachtige manier alle aspecen van het schildersoeuvre van Felix Nussbaum. We ten van het schildersoeuvre van Felix Nussbaum. We Orden or werken ble waren in het bezit van de mensen aan wie hij ze uit ven of ken of verkocht. De (her)ontdekte doeken van Felix in Duitsland, tijdens en gropstentoonstelling. De in Duitsland, tijdens een groepstentoonstelling. De prats in Nederland (Frans Haonstellingen vonden 1982), in Belgie (Goethe-Institur, Brus, 1982), 1982), in Belgie (Goethe-Institut, Brussel, 1982), in (Musée d'ut l'hisoir du Jud 1985), in Fan) (Musee dartet dhistoire du Judaisme, Parijs, 2010) en in het Kulturg Duichtliches Museum in Osn is in het Kulturge een recent aanjekochte collectie van teken ingen en schilderijen. De De stan noor jan de seslissing om hem zijn eig De stad neent dan de beshssing om hem zijn eigen lie ook het Joods Museum in Berlijn on the Het die ook het Joods Museum in Berlijn ontwierp. Het Felix Nussbaum Haus Osnabrück ${ }^{\text {opent } z i j n ~ d e u r e ~}$ in 1998. Het uitzonderijke gebouw biedt onderdak eïnventariseerde bestaande werken ${ }^{2}$. (1) http:///www.osnabrueck.de/ffnh/start-fnh.html, geraadpleegd op $29 \mathrm{ja}-$
nuari 2018 .

(2) Het 'Werkverzeichnis' uitgegeven door de Felix Nussbaum Founda-
tion, bewerkt door Sybille Schwetter, omvat 477 werken
Met uitzondering van een videoproductie, gefiancierd door de stad Osnabrück voor het museum (Niehaus 2000), werd er nooit een documentaire ( gench te beschijven. De film van Lydia Chagoll is baum te beschrijven. De film van Lydia Chagoll is

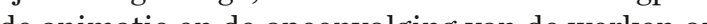
(de anis als in zijn didactish wan de werken op han de chtergondinfortie). Op die manier komen de chen talenten aan bod, een niecwe aanvilling voor het meling werken dat an Nussbaum werd gewijd. Ee ieuwe a in de in het het algemeen. Hem nog ang

Felix en Felka in BrusVan

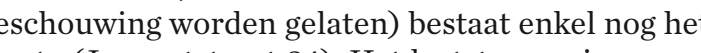
1937 tot ann hun deportatie laatste waarin ze van destrat in de Leopoldwijk, werd in 1983 a che esstrat, inde Leopoldwik, werd in 1983 a gebroken het verblijf van het kun kantoren. Het enige dat aan wat, is

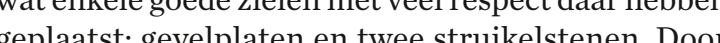
geplaatst: gevelplaten en twee struikelstenen. Door iet nijks beschelangijkste van zijn werken laten schieten, maar tevens de on bieden van het Anne Frank Huis in Amsterdam nen bieden van het Anne Frank Huis in Amsterdam, Orgelman uit 2014 d ut ge in zijn opmis Feld in Frans. Lydia Chagoll draagt dit museum zonder twijfe een warn hart toe, zeker als je ook nog eens bedenkt wathaar ankopese Unie die zo prominent ook de de nodige impulsen zouden geven.

$$
\begin{gathered}
\text { Daniel Weyssow } \\
\text { (Stichting Auschwitz - vzw Auschwitz in Gedachtenis) }
\end{gathered}
$$

$$
\text { Vertaling uit het Frans: Rita Roggen }
$$
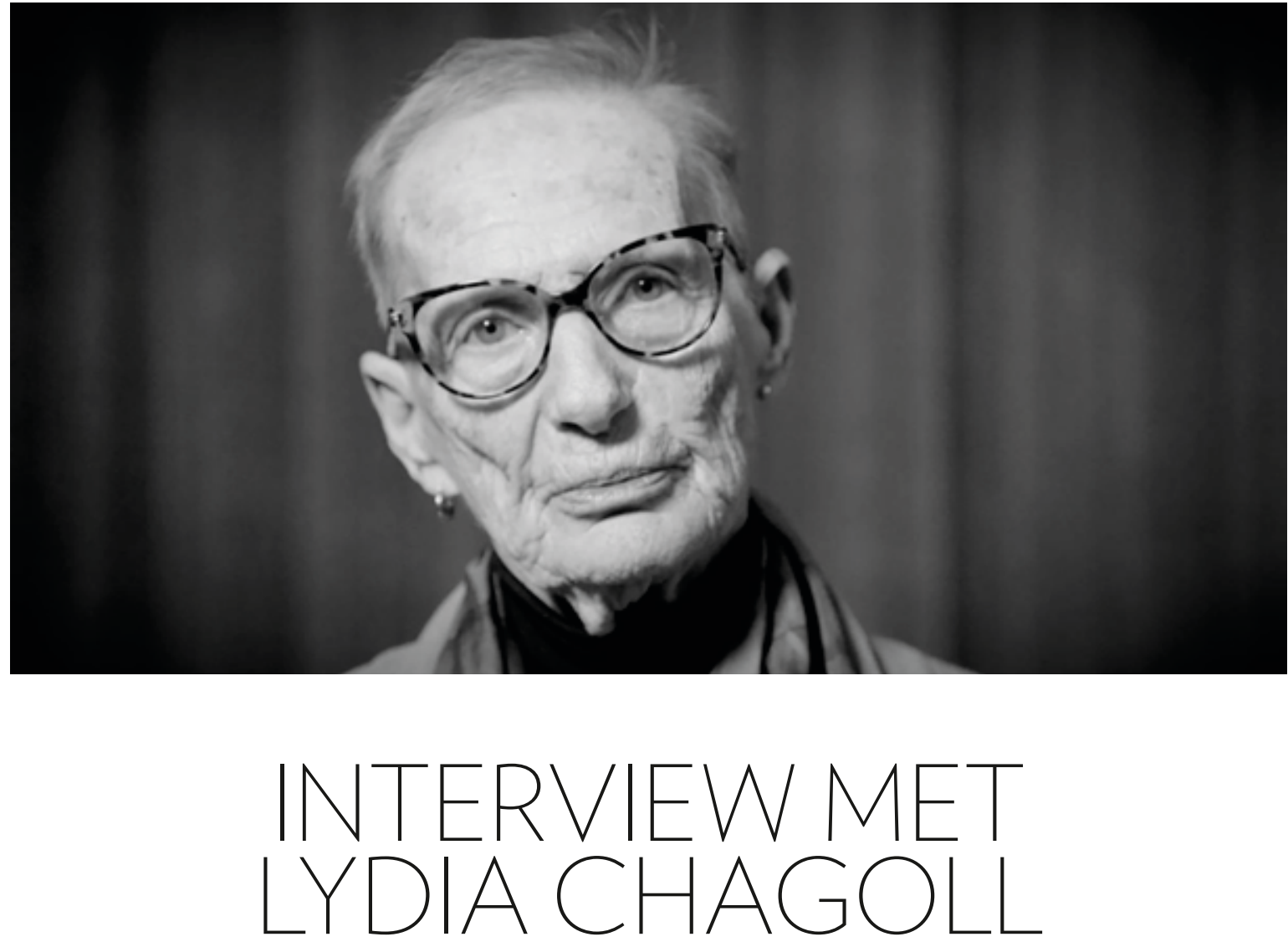

DW: De verschillende visies zijn geen storend element in de film. Integendeel. De doeken van Nussbaum zijn als een dagboek van talrijke belevenissen, vaak geborduurd op een symbolisch stramien om de samenhang duidelijk te maken. De structuur van je film is trouwens heel interessant. Je volgt zijn leven en dan.

LC.... zonder rekening te houden met de chronologische volgorde.

Inderdaad, eerder door de thema's te verbinden. Je loopt heen en weer door de tijd. Je komt terug op . en begrijpen. De toon van je film is erg oprecht, gevoelig Nuss um Je herke bij hem besist ervaing uit je Nuschan Je herkent bijhem beslistervaringen uit je eigen leven?
Ja. Ik ben heel lang een vluchteling geweest. On te beginnen in Frankrijk, in gesloten centra. We zijn vanuit Brussel vertrokken om heel Frankrijk te doorkruisen, richting Toulouse. Ik heb Abbeville moegemakt vier ongelofelijk veel geluk hadden Bij onze aankom tonden we tegenover tion We aarzeld tion. We aarzelden om naar binnen te gaan. Nadat $h$ Neen, neen,'s And er was ook geen station meer.

Was er een bom op gevallen?

De Duitsers hebben het gebombardeerd. Toevallig Dilden niet dat de Engelsen weer zouden inschepen. Dat was het begin van de oorlog. Die heb ik meege- ... . 
- maakt in De Panne, in Saint-Omer. Het was vreselijk Erger dan hier. Er waren ontzettend veel Belgen onderweg. En dan al die Stuka's op de wegen. En naarmat we Duinkiken eken, gewonden

Jullie zijn dan in Toulouse beland?

In een Nederlands vluchtelingencentrum ${ }^{3}$. Het was een groot park waarin een kasteel lag, in La Fourdelijke. Mijn zuster en ik moesten darvoor boetenVolwa. Menen zijn laf. De kinosten daarvoor boeten. volwassenen zijh laf. De kind pesten.

En dan hebben jullie zowat anderhalfjaar nodig gehad om de visa te krijgen...

Een jaar om de toelating te krijgen om via Spanje naar Portugal te gaan. En eens in Portugal aangekomen, mochten we er niet blijven. Misschien konden we naar een kolonie gaan? We werden op een boot het was mo̧ Marques (Mozanbique) gezet, maar het wa frika. Wilitari han Zuid-Afrika op de boot na manu militari van Zuid-Afrika op de boot naar het he Pear na Pearl Harbor. Van de boot zijn we regelrecht naar lid kare ver id waren van de Vijfde Colonne of gemeen gespuis. $E$ waren niet alleen Joden die Europa hadden verlaten,

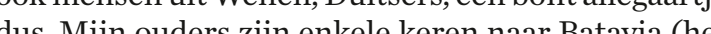
dus. Mijn ouders zijn enkele keren naar Batavia (het huidige Jakarta) gevoerd voor een politieverhoor. En tien of elf. We werden weer op een boet gezas toen tien of elf. We werden weer op een boot gezet en to zuster en ik in viif Japanse vrouwenkampen, terwij zuster en ik in vijf Japanse vrouwenkampen, terwij lo krijosgevangenenkampen.

Wat Nussbaum betreft: ook hij moest in ballingschap, omwille van eenzelfde afkomst, naar de kampen.. (3) Noot van de vertaler: de passages uit Buigen in jappenkampen (1986)
En ook gedurende die ballingschap met vieren in enertjes wonen, het ene al erbarmelijke dan de vlekken op de smerige muren. Walgelijk.

Er is ook de gemeenschappelijke aantrekkingskrach an de kunst. Hij schilderde. Jij was danseres, choreografe, filmregisseur, je schreef boeken.

Ik heb veel gevoeld, zonder het te zeggen. Ik trek geen parallel met mezelf. Mark Schaevers, die het boek

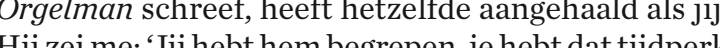
Hij zei me: Jij hebt hem begrepen, je hebt dat tijdperk e zijn, jij kent het gezeik...'

Er is nog een sterk punt, namelijk het sterke verlangen kn die taak, die noodzaak, duidelijk heel moeilijk concretiseren. Het valt op met hoeveel nadruk hij bijvoorbeeld probeert de toeschouwer te
boeien.

Ja, maar hij vervalt nooit in sadisme of sentimentaliteit.

Altijd op afstand, maar met een boodschap. Hij heef eprobeerd om de aandacht te vestigen op heel veel dingen, om erop te wijzen.

Als je goed kijkt, ontdek je in zijn schilderijen ontzettend veel symbolen.

Hoe zeg je de dingen als je ze wilt doorgeven? Dit ort ervaringen kun je niet delen..

Je kunt zelfs niet zeggen: 'Wij hadden honger.' De doorsnee sterveling weet niet wat dat betekent. Neem bijvoorbeeld iemand die om zeven uur opstaat, ontbijt en een beetje hongerig is tegen de middag. Hij gaat zeggen dat hij honger heeft. Neen, hij heeft trek, hij wil iets niet hebt echte honger is, kun je niet weten als je het niet hebt meegenaakt. En over die problemen heb ik het niet gehad. Maar de mensen kennen bijvoorbeel wel de rantsoenbonnen. Welnu, Nussbaum probeer deze extreme armoede aan te tonen, te doen begrijpen Je voelt dat dat voor hem belangrijk is en ik toon dat. Je Kijk eens naar hun villa. Een mastodont. Akkoord, zijn vader werkte hard, het was een good businessman die hield van geld. Hun vakanties brachten ze altijd door in Norderny Niet mer welk Ik kan nietzergen hoe vak me

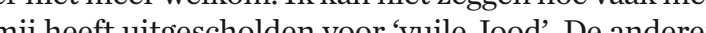
Je uitgescholden voor 'vuile Jood. De ander

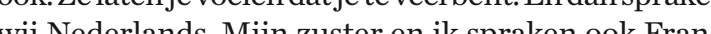
wij Nederlands. Mijn zuster en ik spraken ook Fran Tansman, dienuechteentalenknoble F Duis. Wijwarch

Waar en hoe heb je het werk van Nussbaum ontdekt? En wanneer heb je het idee opgevat een film over hem te maken?

Ik heb met Frans Buyens ${ }^{4}$ een film gemaakt ove het fascisme en de Japanse en nazidictators. Alle bij elkaar negen uur. De helft bestond uit historisch Frale en de andere uit interviews met verzetslu, Franstaligen en Vlamingen, mannen en vrouwen, comm nisten en katholieken. René Reindorf maakte daar deel van uit. Hij was de enige Jood in de film. We

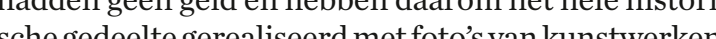
Zo heb ik Nussbalis Zo heb ik N. We hebb ontekt, in 1990. En ik werd er verliefd op. We hebben alles gekocht wat we over hem vonden, maar ik was besluiteloos en maakte andere treep Het boek van Mark Schaevers heeft mij over streep gehaald. Ik merkte dat er plots belangstelling was ontstan voor Nussbaum. Ik ben naar Osnabrück naar het Nussbaun-Museum gegaan. Ik heb er een ontmoeting gehad met de directrice. Dan kreeg ik zin om die flm te maken, echt zin. Ik vond dat ik hulde moest brengen aan die kunstenaar. De grootste kun. en Fix gelegenheden geweest om zijn oeuvre te ontdekke in een tentoonstelling van format. Het museum in Osnabre verzameld. Je vindt deelvanzijh onvangrijke ouvre verzancld. Je vindt engeveer tweehonder De volgendi

De volgende stap was telefoneren naar de eigenaars van schilderijen van Nussbaum, meer bepaald

(4) Frans Buyens (1924-2004), partner van Lydia Chagoll, regisseur van
talrijke documentaires en 'geengageerde' fictie. (5) René Raindorf (1918-1998), overlevende van Auschwitz. Samen met
Paul Halter, Maurice Goldstein en Henri Goldberg was hij stichter van de Stichting Auschwitz. in Tel Aviv en Berlijn. En dan heb ik besloten om het heft in eigen handen te nemen. Jammer genoeg heb ik een fin

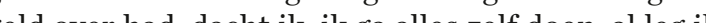
. onderzoek gedan. Ik heb het scenario geschreven, de Franse, Engelse en Duitse vertaling gchreven, che ridm was nog om men die me zouden kun was ne ertoe te bewegen mij geen exorbitant hoge bedrage het

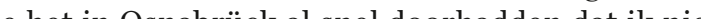
de minste subsidies had en een miniem budget. $Z$ Co hebben me gezegd dat ik enkel het werk in het foto. hadiderijen in mijn film. Over. elders heb ikm vee copyright voor de foto's moten betalen: in Tel Aviv, Berlijn en Holland.

\section{Heb
scenario?}

je geen hulp ingeroepen voor de tekst, het

Neen, ik heb het zelfs niet laten nalezen. Ik had anvankelijk aan Mark Schaevers gevraagd om het senario samen met mij te schrijven, maar hij von hetbeter om mij mijn eigen ideeën te laten uitwerken.

Dan wil ik het nu hebben over de techniek. Hoe ben je op het idee van de voorstelling en het ritme voor $d$ je op het idee van de voorstelling en $h$,
volgorde van de schilderijen gekomen?

Dat heet creativiteit. Ik kijk, ik zoek interessante elementen die ik kan gebruiken. En ik zoek een rode draad. I ben niet zo'n voorstander van juiste chronopre pat at man in . che verk vaak voorkomt, of telefoon- en telegrafiepalen.

Je hebt nogal veel aandacht gevestigd op die communicatiefactoren.

Ja, omdat Nussbaum heel moeilijk kan commuiceren. Hij was op zoek naar zichzelf. Het standpunt van kunsthistoricus is interessant. Nussbaum neemt $\bullet \bullet$ 
•. de dingen op als een spons. Hij zet zich op de plaats van andere schilders en begint te oefenen. In zijn werken vind je ond andreverwijzingen naar Chirico, Beeckman, Meidner. Maar doorheen al die geleende stijle cen the valder. een groot schilder.

Om in België te blijven rechtvaardigt Nussbaum zijn anwezigheid tegenover de burgerlijke stand door ui te leggen dat hij de Vlaamse schilderkunst bestudeert, wijfel wa de de ijn ijn werken.

Hij stond in elk geval dicht bij de schilderkunst van Edgard Tytgat. Dat blijkt bijvoorbeeld uit heel wat va de schild kleuren komenvan Tytgat. En tochis hetniet Tytgat. E wern

Hij leent van schilders die hij waardeert, maar niet van de avant-garde, behalve dan van de Nieuwe Zakelijkheid de avant-garde, behalve dan van de
en de metafysische schilderkunst.

Dat klopt. Die interesseerde hem niet.

Welke rol heeft zijn echtgenote Felka Platek aan zijn zijde gespeeld?

Ik heb respect voor zijn echtgenote, die voor de oor$\log$ in het getto van Warschau woonde. Er blijft nie meer veelover van haar oeuvre. Ze was heel moederlijk

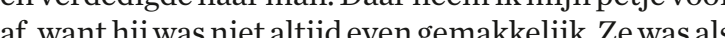
at, want hij was niet altijd even gemakkelijk. Ze was al vchilder eerder doorsnee, wellicht een beetje opperdie ze hild was ze silderde, mooier wilde voorsteller de portretschilder.

Waarom neemt het orgel zo'n centrale plaats in zij werk in?

Ikheb de indruk dat niemand die vraag totop heden heeft beantwoord.

\section{Is er een verband met het religieuze?}

Neen. Het is een straatinstrument.

Had Nussbaum belangstelling voor de straatmuzikanten en -artiesten?

Ik vind hem een diplomaat. Dat zeg ik trouwens bij het begin van de film. Dat is een persoonlijke interpretatie. Toen ik dat geweldige grote schilderij Der tolle Platz zag, begreep ik dat hij redeneerkracht had, een voorgevoel voor gebeurtenissen. Max Liebermann, die na de oer otogvoozitter dat op in vorgesteld op het dak van zijn patriciershuis dat op instorten staat. Op het ogenblik waarop NussDeperson schistert Deperd, ceerd, allemaal zo klein.... Voor mij is dat de aankondiging van mensen die niet meer zelf denken. Ze volgen Hitler. Dat is mijn interpretatic. Met dat schilderij heeft men gezegd: dat is dejonge nieuwe schilder. Men begon hem ling vond hij geen gehoor. Dat is vreselijk en dat heeft he, vond hij geen gehoor. Dat is vreselijk en dat heef in gevoelens het is niet no die te schildeijen kijkt, worterveeldidelijk. kt, wordt er veel duidelijk

Is het mogelijk dat de verloren, vernietigde of nie eïnventariseerde doeken van Nussbaum weer opduiken?

\section{Neen, dat denk ik niet.}

In welke steden bevinden zich de voornaamste collecties?

In Tel Aviv en in Berlijn. In Brussel zijn er drie in het Joods Museum. Door de oorlog werd het leven van Nussbaum helemaal overhoopgehaald. Vele van zijn doeken werden door privépersonen gekocht. Sommigen hebben hem geholpen, anderen hebben misbruik gemaakt van de omstandigheden. Men heeft hem zelfs overgeleverd aan de Gestapo. Dat zegt alles. Ik heb de namen van die personen niet willen noemen in de film, omdat ik wilde dat de mensen geconcentreerd blijven op de schilderijen. Ik wilde die film echt maken als een soorttentoonstenling, on de kanste bied
Wordt je film verdeeld?

Ik weet dat ik films kan maken en ik weet ook dat ik niets afweet van zaken doen... Ik heb de film deze week opgestuurd naar de Dossinkazerne, het Museum voor hedendaagse kunst in Oostende (Mu.ZEE) en het huseum van Osnabrück. Ik zou zo graag hebben dat van de hoop dat hij in Osnabrück wordt vopepte doen. hoop dat hij in Osnabrick wordt voorgesteld. In het museun zelf zou het

\section{Hartelijk bedankt, Lydia, voor dit onderhoud.}

Opgetekend op 25 januari 2018 door Daniel Weyssow (Stichting Auschwitz - vewAschedachtenis) Vertaling uit het Frans: Rita Roggen $\rightarrow$ Biblio- en filmografie

$\checkmark$ Lydia Chagoll, Buigen in jappenkampen, Leuven: Uitgeverij

$\checkmark$ Michael Niehaus Lasst meine Bilder nicht sterben!' Felix Nussbaum (1904-1944) [film], uitgegeven door Elke Schnieders, Kulturgeschichtiches Museum Osnabruck Felix-Nussbaumaus, geproduceerd door MM-TV/Felin-Nussbans Haus, $\diamond$ Mark Schaevers, Orgelman. Felix Nussbaum, een

Wilt u de dvd Felix.Nussbaum (duur 75) van Lydia Chagoll aankopen?

Mail naarbcocdinfo@telenet.be met vermelding of u de Nederlandse, Engelse, Duitse of Franse versie wenst. Prijs voor privégebruik en gebruik in scholen: 25 euro inclusief verzendingskosten.

Prijs voor organisaties en voorstellingen met betalend publiek: 150 euro inclusief verzendingskosten. 